\title{
Considerações sobre a Dimensão Biológica do Conceito de Pulsão em Freud ${ }^{1}$
}

\author{
Maria Nadeje Pereira Barbosa \\ Manoel Antonio dos Santos ${ }^{23}$ \\ Universidade de São Paulo, Ribeirão Preto \\ Universidad Complutense de Madrid
}

\begin{abstract}
Resumo
Neste artigo postula-se a existência de uma dimensão biológica do conceito de pulsão na obra de Freud, relacionada com o enigmático da gênese e do desenvolvimento do aparato psíquico. Considerando que no pensamento freudiano existe uma tensão entre duas modalidades discursivas, a primeira relacionada com os desenvolvimentos da hipótese estrutural sobre o inconsciente, e a segunda que funciona como centro gravitacional de teorizações provenientes da fisiologia e da biologia, estabelece-se determinadas linhas de força que atravessam o pensamento freudiano, designadas como variantes evolucionistas e decompostas em variantes evolucionistas-ontogenéticas-derivativas, evolucionistasfilogenéticas-instintuais e evolucionistas-ontogenéticas constitutivas. Ao final do artigo, conjectura-se que com a expansão da psicanálise talvez seja possível traduzir numa linguagem metapsicológica os aspectos fronteiriços da reflexão freudiana.
\end{abstract}

Palauras-chave: Pulsão; Freud; psicanálise; biologia.

\section{Considerations about the Biological Dimension of the Instinct Concept in Freud}

\begin{abstract}
In the present report we postulate the existence of a biological dimension implicit in the concept of instinct in Freud's work, related to the enigmatic nature of the genesis and development of the psychic apparatus. Since in Freudian thought there is a tension between two discourse modalities, the first related to the developments of the structural hypothesis about the subconscious and the second functioning as a gravitational center for theoretical constructs derived from psysiology and biology, certain lines of force are established which permeate Freudian thought, designated as evolutionary variants and broken down into evolutionary-ontogenetic-derivative, evolutionary-phylogenetic-instinctive and evolutionary-ontogenetic-constitutive variants. At the end of the article we propose that, with the expansion of psychoanalysis, it might perhaps be possible to traslate into a metapsychological language the frontier aspects of Freudian reflection.

Keywords: Instinct; Freud; psychoanalysis; biology.
\end{abstract}

A expansão da disciplina fundada por Freud permite identificar pontos de inflexão que conduzem ao estabelecimento de novos descobrimentos e à formulação de novas hipóteses. $\mathrm{O}$ exame de tais desdobramentos orienta nossa atenção para alguns aspectos tensos do pensamento freudiano, recorrendo a uma expressão de Sandler (1982, p. 580), em consonância com o fundamental que se depreende de tal expansão, relativizando determinadas formulações, recusandoas veementemente, ou buscando nelas um esclarecimento, sem que isso implique em alterar seus postulados fundamentais.

O conceito de pulsão (Trieb) na obra de Freud, objeto desta tripla tendência, revela sua fecundidade na medida em que a discussão sobre seu valor heurístico deu lugar a diferentes orientações psicanalíticas, que são uma das expressões mais significativas da expansão da psicanálise. Contudo, os aspectos obscuros que persistem na teoria freudiana das pulsões reconhecidos inclusive por Freud $(1925 / 1996)^{4}$, conduziram alguns autores a introduzirem novas teorizações e definições, sem se aterem à coerência destas reformulações em relação ao conjunto da teoria. Ou seja, em lugar de analisarem as ambigüidades existentes na teoria pulsional e proporem soluções

\footnotetext{
${ }^{1}$ As idéias centrais do presente trabalho foram expostas na $56^{\mathrm{a}}$ Reunião Anual da Sociedade Brasileira para o Progresso da Ciência, no ano de 2000, em Brasilia, DF.

${ }^{2}$ Agradecemos ao apoio institucional dado pelo Conselho Nacional de Desenvolvimento Científico e Tecnológico (CNPq) para a realização do presente trabalho.

${ }^{3}$ Endereço para correspondência: Departamento de Psicologia e Educação, Faculdade de Filosofia, Ciências e Letras de Ribeirão Preto, USP, Av. Bandeirantes, 3900, Cidade Universitária, 14040 901, Ribeirão Preto, SP. Fone: (16)6023645; Fax: (16)6023851. E-mail: masantos@ffclrp.usp.br

${ }^{4}$ Em Um estudo autobiográfico (1925/19961) diz Freud: "Não há necessidade mais premente na psicologia do que uma teoria dos instintos firmemente alicerçada, sobre a qual talvez então fosse possível formular outros pontos. Contudo, nada disto existe, e a psicanálise é impelida a envidar esforços especulativos no sentido de tal teoria"(1925/1996l, p. 60).
}

conseqüentes, estabeleceram um amálgama de novos conceitos que geralmente mais confundem do que esclarecem. O resultado não é somente uma teoria das pulsões incompleta, mas também a recusa atual que alguns autores demonstram em relação a essa questão.

Por outro lado, paulatinamente vem sendo reconhecida a peculiar maneira com que Freud introduz teorizações da biologia no seu discurso. Paulatinamente porque, mesmo em posição de destaque, as raízes biológicas da psicanálise foram tomadas em consideração apenas a partir do eminente estudo de Sulloway. Este autor assinala que o próprio Freud, mesmo concebendo o homem como entidade biológica, não insistiu nas raízes biológicas da psicanálise, e que a maior parte das concepções fundamentais de Freud são de ordem biológica, tanto na sua inspiração, como nas suas implicações (Sulloway, 1981).

Pois bem, o conceito de pulsão, tal como Freud o formula, apresentaria características de outro campo do saber, mais especificamente, da biologia? Qual é a relação entre o conceito de pulsão e biologia, a partir do estabelecimento da hipótese estrutural sobre a sexualidade inconsciente? É possível postular no pensamento freudiano uma dimensão biológica do conceito de pulsão?

O presente trabalho propõe algumas sendas que permitam esclarecer estas questões teóricas, esboçando algumas considerações sobre a possível influência que as idéias evolucionistas exerceram na construção do conceito freudiano de pulsão. $\mathrm{O}$ que se pretende demonstrar é que, mesmo reconhecendo que a partir do estabelecimento da hipótese estrutural sobre a sexualidade inconsciente, hipótese que fundamenta a psicanálise como disciplina, o biológico da pulsão (da mesma maneira que o seu aspecto psicológico) assume, ineludivelmente, um caráter metapsicológico. 
$\mathrm{Na}$ verdade, Freud recorre ao saber da biologia para fundamentar determinadas hipóteses da sua teoria das pulsões que, inseridas nos albores da disciplina fundada por ele, mostravam-se obscuras aos olhos do próprio Freud. O que permite postular, no cerne do pensamento freudiano, uma dimensão biológica da pulsão, vinculada aos aspectos cruciais da reflexão psicanalítica ou, o que resulta no mesmo, ao caráter enigmático da gênese e do desenvolvimento do aparelho psíquico.

Uma possível objeção ao tema que será tratado nas próximas linhas é a eleição unilateral de um determinado aspecto da pulsão (o biológico) em detrimento de uma reflexão mais ampla, que inclua o psíquico. Entretanto, prefere-se manter uma certa prudência metodológica em relação às formulações de Freud nas quais o conceito de pulsão aparece atado ao biológico, com a finalidade de detectar as dificuldades que surgem no plano da teoria pulsional. Tratar de um aspecto da pulsão que se apresenta obscuro não somente no interior do pensamento freudiano, mas também nos desenvolvimentos psicanalíticos posteriores a Freud, contribui para a consecução deste objetivo.

Em outro estudo (Barbosa, 2001), foram assinalados os elementos da dimensão biológica incompatíveis com a hipótese sobre a sexualidade inconsciente, a saber: a concepção de sexualidade desde o ponto de vista instintual em detrimento do pulsional; a concepção que trata sobre a origem e a evolução do aparelho psíquico nos termos de adaptação à realidade; e a concepção da meta da sexualidade nos termos estritos de reprodução das espécies. Ali, asseverou-se que, paradoxalmente, alguns destes elementos aparecem na obra de Freud, mesmo considerando-se a mudança radical que uma reflexão propriamente psicanalítica sobre a pulsão produz no seu pensamento.

No presente trabalho, estes assinalamentos servirão de índice para postular a existência de uma dimensão biológica do conceito de pulsão no pensamento freudiano, assim como sua amplitude e complexidade. A tendência de Freud em não ser somente um espectador dos avanços da biologia do seu tempo, mas também procurar dar uma versão psíquica a estes desenvolvimentos, mesmo assumindo o risco de solapar seus próprios descobrimentos, dá um significado especial a esta dimensão.

Dentro desta mesma ordem de considerações, o rastreamento de uma dimensão biológica do conceito de pulsão tomará como marco a leitura dos seguintes textos de Freud: Três ensaios sobre a teoria da sexualidade (Freud, 1905/1996b), Formulacōes sobre os dois princípios do funcionamento mental (Freud, 1911/1996e) e Além do princípio de prazer (Freud, 1920/1996j). Textos que, em linhas gerais, abordam o processo de transmutação que converte a expressão Trieb (pulsão) em conceito propriamente psicanalítico; o lugar que ocupa a pulsão nas teorizações que derivam do primeiro dualismo pulsional, a saber, pulsões sexuais (Sexualtriebe) e pulsões do ego (Icbtriebe), estas últimas incorporadas às pulsões de autoconservação (Sellsterbaltungstriebe); e a reformulação radical da teoria das pulsões, a partir de 1920, com a introdução do segundo dualismo pulsional: pulsões de vida (Lebenstriebe) e pulsão de morte (Todestrieb).

\section{Observações preliminares}

Desde os chamados anos pré-psicanalíticos, o pensamento freudiano apresenta uma abertura em relação aos outros campos do saber, importando explícita ou implicitamente alguns pressupostos científicos do seu tempo na sua estrutura discursiva. Freud era, antes de tudo, um cientista e tinha seu pensamento assentado no mais rigoroso anti-vitalismo alemão.

A partir da hipótese estrutural sobre a sexualidade inconsciente, será possível incluir uma série de expressões, uma das quais a de Trieb, proveniente da filosofia e da fisiologia, transmutá-la numa linguagem psicanalítica e, como conseqüência, ampliar as perspectivas relativas a este conceito. Esse processo é correlativo com o auge de uma reflexão sobre uma tópica dos processos psíquicos que deixará de evocar um aparelho neuronal dotado de lugares anatômicos e dará ênfase à noção de aparelho psíquico (psychischer Apparat), dotado de uma localização psíquica (psychischen Lokalität), tal como Freud esboça no capítulo VII da Interpretação dos sonhos, intitulado $A$ psicologia dos processos oníricos (Freud, 1900/1996a).

A perspectiva tópica, genuinamente freudiana, segundo Anzieu (1989), evocaria assim um lugar e um tempo psíquico outro, dotado de uma realidade e de uma temporalidade específica do campo psicanalítico.Temporalidade outra que, baseando-se no tempo da consciência e do biológico, inscreve uma falha, uma ferida, uma frustração e introduz o fora do tempo (Zeithos), segundo as palavras de Kristeva (1998, pp. 114-115). Lugar outro em que a formulação sobre a pulsão adquire um especial destaque; como assinala Ricoeur (1970), existem lugares porque existem relações de força que são relações de exclusão (resistência, defesa e proibição) (Ricoeur, 1970, p. 105, tradução dos autores). Estas considerações remetem diretamente às relações entre a pulsão e a tópica dos processos psíquicos.

Com o estabelecimento da hipótese estrutural sobre a sexualidade inconsciente, dá-se início a uma operação teórico-clínica que converte as reflexões assentadas no saber positivo numa modalidade de reflexão metapsicológica. Entretanto, não se trata de uma operação totalmente lograda, sobretudo quando se cotejam as reflexões que se depreendem da hipótese estrutural com o movimento do pensamento freudiano nos anos posteriores ao estabelecimento desta hipótese. Freud, no decorrer de sua extensa obra, busca fundamentar conceitos propriamente psicanalíticos, ou seja, derivados da observação clínica, com hipóteses derivadas da biologia. Se, por um lado, a transposição efetuada por Freud revela seu talento na medida em que logra converter os modelos biológicos em metáforas e em analogias, por outro, estes modelos somente são úteis na medida em que constituem um apoio provisório ao pensamento, tal como adverte Perron (1991).

Com efeito, situando estas formulações no seu contexto original, é possível deduzir que este procedimento de Freud está situado em um momento temporal da disciplina fundada por ele em que o recurso à biologia contribuía para a fundamentação das hipóteses propriamente psicanalíticas, permitindo a instauração de novos desdobramentos, que conduziam a novos descobrimentos e à formulação de novas hipóteses. Assim, o recurso à biologia se dá quando o movimento do pensamento freudiano não dispunha de instrumentos para explicar o transcurso dos processos psíquicos, ou, o que resulta no mesmo, a biologia no pensamento freudiano está 
relacionada com o caráter enigmático da gênese e dos movimentos do aparelho psíquico.

O que termina por desvelar as tensões produzidas entre duas modalidades discursivas, nas quais o conceito de pulsão aparece como base. Se a primeira, que tratamos de delinear nas páginas anteriores, está enlaçada com os desenvolvimentos da hipótese estrutural sobre a sexualidade inconsciente e encontra nos conceitos de fantasia (Phantasie) e desejo (Wunshl) a base das formulações que dão à psicanálise toda a sua originalidade, a segunda, que constitui o foco de interesse deste trabalho, funciona como centro gravitacional de teorizações provenientes da biologia e da fisiologia.

No que se refere à dimensão biológica do conceito de pulsão, esta segunda teorização apresenta determinadas linhas de força que atravessam o pensamento freudiano e que, a partir de agora, serão apresentadas e situadas nos textos de Freud dos quais foram extraídas. São as variantes evolucionistas, que podem ser decompostas em evolucionistas-ontogenéticas-derivativas,evolucionistas-filogenéticasinstintuais e evolucionistas-ontogenéticas-constitutivas do conceito de pulsão.

\section{Variantes evolucionistas do conceito de pulsão}

A adesão inicial de Freud à teoria evolucionista, presente desde suas pesquisas como neurólogo, tal como assinala Gay (1989), marcará sua presença no desenvolvimento das suas hipóteses propriamente psicanalíticas. Jones (1997) descreve as contribuições de Freud à teoria da evolução no decorrer da sua obra, mesmo reconhecendo que seus aportes ao campo da biologia foram mais acidentais que deliberados.Com efeito, as idéias expostas no Projeto para uma psicologia cientifica (Freud, 1950/ 1996m), obra póstuma de Freud e marco propriamente teórico da introdução da expressão Trieb, revelam que o recurso às hipóteses do campo da biologia constituem um poderoso ingrediente no processo de elaboração das suas hipóteses que encontravam na teoria da evolução uma base comum, assim como no que de original se deduz do desenvolvimento da noção de aparelho psíquico, a qual culmina com o estabelecimento da hipótese estrutural acerca da sexualidade inconsciente. Estas considerações sublinham a importância do Projeto... (Freud, 1950/ 1996 m) em relação ao conjunto de sua obra, mesmo considerando-se que as idéias expostas neste trabalho somente assumiriam um estatuto metapsicológico quando a tópica dos processos psíquicos evocar a outra modalidade discursiva dotada de uma concepção peculiar de realidade e de temporalidade em relação a da consciência e da biologia. Neste sentido, seria o entendimento acerca da natureza sexual da representação reprimida, vinculando sexualidade, inconsciente e repressão, ou, em outros termos, vinculando a sexualidade com a tópica dos processos psíquicos, que tornará possível desenvolver uma reflexão psicanalítica sobre o encontro subjetivo do organismo com o outro da ação específica (sperifische Aktion), sem nenhuma classe de reducionismo biologista e psicologista.

De uma obra como os Três ensaios... (Freud, 1905/1996b), marco propriamente psicanalítico da introdução da expressão
Trieb no pensamento freudiano, depreendem-se duas linhas de força relativas a este conceito, inseridas numa teoria genética- evolucionista que, paradoxalmente, coexistem não somente no decorrer das sucessivas edições que compõem esta obra $(1905,1910,1915,1920$, 1922, 1925), mas no seu pensamento como um todo. Estas linhas de força demonstram as vicissitudes da adesão de Freud às hipóteses evolucionistas, assim como as conseqüências que decorrem desta adesão, a saber, as variantes evolucionistas-ontogenéticas-derivativas e evolucionistas-filogenéticas-instintuais.

Assim, é possível afirmar que, se é certo que Freud recusa a dimensão instintual (com metas e objetos específicos) em detrimento da sua formulação sobre a pulsão (que carece de orientação fixa), e sustenta a hipótese sobre a contingência do objeto da pulsão, também é certo que introduz a dimensão biológica nas suas características genético-evolucionistas.

As variantes evolucionistas-ontogenéticas-derivativas são variantes que abordam a gênese ontogenética e a evolução da pulsão, decomposta nos seus componentes pré-genitais e em relação dialética de derivação com o instinto (Laplanche, 1973), embora a pulsão seja descrita em termos de realidade biológica, ou seja, endógena. As pulsões também se inserem numa temporalidade que, mesmo se perfilando segundo os mesmos termos da biologia (linear, cronológica, abarcando tanto um sentido progressivo como regressivo), apresentam uma meta, a satisfação, que aponta a uma concepção dinâmica da sexualidade.

Na primeira edição dos Três ensaios...(Freud, 1905/1996b), de 1905, Freud concebe a sexualidade infantil como um estado de anarquia e de poliformismo pulsional. As pulsões parciais (Partialtrieben) auto-eróticas (pulsão oral, pulsão anal) apresentam modos de satisfação independentes que predominam em determinadas etapas do desenvolvimento psico-fisiológico do sujeito, e que atuam em tal ou qual parte do corpo, propícias também ao engendramento da excitação, as chamadas zonas erógenas (erogenen Zonen). Este funcionamento anárquico gradualmente se converte numa organização (Organisation) a partir da puberdade; as pulsões parciais dispersas se convertem em alo-eróticas e se submetem a um único modo de satisfação: as zonas erógenas ficam subordinadas à primazia da genitalidade (Freud, 1905/1996b).

Depreende-se, assim, uma concepção de evolução nos termos de progressão do mais simples (as pulsões parciais da sexualidade infantil) ao mais complexo (a pulsão sexual da organização genital adulta). Concepção que também inclui a hipótese sobre uma reversão desta evolução no caso das enfermidades mentais. No pensamento freudiano, esta reversão é tratada como uma fixação (Fixierung) nos termos de inibição do desenvolvimento que dissocia a organização e que, à exceção de certas perversões, prepara as posições em que opera a regressão (Regresion) da libido, tal como assinalam Laplanche e Pontalis (1983) no Vocabulário da Psicanálise.

Com os avanços da teoria da libido, que se esboçam nas sucessivas edições que compõem os Três ensaios... (Freud, 1905/1996b), em particular, com a introdução propriamente psicanalítica do conceito de narcisismo (Narcissmus), Freud outorga o valor de organização à sexualidade infantil. Nota-se, então, seu interesse em aprofundar sua 
reflexão sobre a teoria da libido a partir do estudo sobre as neuroses de transferência e da psicose. Tal teoria se iniciou a partir da importância atribuída ao erotismo anal em Caráter e erotismo anal (Freud, 1908/1996c), para, em $A$ disposição à neurose obsessiva (Freud, 1913/1996g), introduzir a hipótese de um estádio anal. Dentro desta mesma ordem de considerações, na terceira edição dos Três ensaios... (Freud, 1905/1996b), de 1915, Freud introduz a hipótese de um estádio oral e, finalmente, em $A$ organização genital infantil (Freud, 1923/19961), a de um estádio fálico no desenvolvimento da libido.

Esta alteração é muito significativa no pensamento freudiano; o estabelecimento de estádios no desenvolvimento libidinal indica que não se trata mais de uma concepção de evolução de unidades mais simples em direção a unidades mais complexas, mas da coexistência de duas organizações, a infantil e a adulta, que separadas entre si pelo período de latência (Latensperiode) buscam abarcar os avatares da sexualidade humana. Assim, o advento da sexualidade adulta, com a primazia da zona genital e o reconhecimento do objeto total, não se inscreve no sentido de que este último estádio, no tempo cronológico, excluísse os anteriores, ou seja, os modos pré-genitais de satisfação da libido, mas somente se sustenta desde que mantendo uma relação dialética com aquele.

Laplanche e Pontalis (1983) consideram que esta mudança de perspectiva conduziu a uma nova extensão da noção de fixação. Mais do que fases do desenvolvimento da libido, a fixação engloba também a estrutura da atividade característica de cada etapa, que inclui não somente a atividade sexual e a escolha de objeto, mas também o modo como o sujeito concebe suas experiências intra e intersubjetivas. Por certo, as perversões revelam a detenção da evolução da pulsão sexual em um de seus componentes, mas a sublimação (Sublimierung) também revela a não integração da pulsão sexual. Assim, é possível detectar no adulto modos orais e anais de satisfação e não há porquê considerá-lo necessariamente perverso por não querer ou não poder procriar.

Convém sublinhar que foi mediante este proceder que Freud pôde ampliar a teoria da sexualidade humana em relação às doutrinas clássicas. Com efeito, foi em função de uma concepção evolutiva da sexualidade humana que foi possível aproximar a sexualidade infantil à sexualidade perversa, introduzir a hipótese sobre a fixação e regressão da libido, sem mencionar o pressuposto de um estádio fálico no desenvolvimento da libido, assim como o reconhecimento no adulto de um funcionamento sexual caracterizado por modos orais e anais de satisfação. $\mathrm{O}$ que desvela uma concepção de evolução derivativa, na qual a genitalidade não aparece vinculada estritamente à reprodução. Ocorre, entretanto, que a concepção de uma sexualidade endógena converte a dimensão fantasmática - uma das mais significativas descontinuidades do pensamento freudiano - numa "expressão secundária" desta realidade, tal como advertem Laplanche e Pontalis (1988, pp. 40-41).

Pois bem, dentro desta concepção de sexualidade depreendese outra representação de temporalidade, a saber, a instauração bifásica da sexualidade interposta pelo período de latência. Esta concepção já estava presente nos anos anteriores ao abandono da teoria da sedução para explicar a etiologia da histeria a propósito do caso Emma, no Projeto... (Freud, 1950/1996m), a saber, a ressignificação a posteriori de um evento incompreendido e excluído no interior do sujeito que, separado de um segundo tempo por uma série temporal, é retomado na elaboração desse segundo tempo. Entretanto, é transposta em um tempo préhistórico, sugerindo uma fixação que plasmaria seus efeitos na história ontogenética do sujeito, seja na predisposição à neurose, seja nas conquistas sociais e culturais da humanidade. É precisamente desta adesão de Freud a teorias que enfatizam a filogênese da humanidade em detrimento do desenvolvimento ontogenético que se deduz uma segunda linha de força relativa à dimensão biológica do conceito de pulsão, a saber, as variantes evolucionistas-filogenéticas-instintuais.

As variantes evolucionistas-filogenéticas-instintuais tratam-se das teorizações de Freud nas quais, baseando-se em determinadas teorias da biologia, neste caso, na lei bioenergética de Haeckel, segundo a qual a filogênese determina a ontogênese, postula-se o vínculo entre pulsão e filogênese. Estas teorizações atribuem à pulsão uma realidade endógena e hereditária, e desembocam na especulação acerca de uma temporalidade pré-histórica, mítica, ou seja, em teorizações sobre a origem das instituições e das neuroses em que a filogênese aparece como cenário.

A concepção hereditária da pulsão aponta a tentativa de Freud de fundamentar este conceito com uma hipótese tomada da biologia; movimento de um pensamento que, como bem adverte um autor como Laplanche (1993), retornará quando Freud, baseando-se na teoria morfológica de Weissman sobre o plasma germinal, busca fundamentar a gênese do conceito de pulsão de morte a partir dos dados da etologia animal (migração dos peixes e das aves ao seu ambiente de origem) em Além do princípio de prazer (Freud, 1920/ 1996j), tal como se verá mais adiante. Questão, per se, polêmica, uma vez que não consiste em importar um termo ou um modelo da biologia e convertê-lo em metáfora ou em analogia, mas em fundamentar uma conceitualização supostamente psicanalítica a partir de uma hipótese tomada de empréstimo da biologia.

Esta hipotética relação entre pulsão e filogênese desemboca na tentativa de Freud de dar uma versão psíquica às hipóteses de Darwin e de Lamarck sobre a origem e a evolução das espécies, mesmo assumindo o risco de soterrar seus próprios descobrimentos, já que a suposição de uma realidade endógena e de uma temporalidade pré-histórica não é compatível com uma modalidade de reflexão propriamente psicanalítica, nem apresenta fundamento orgânico ${ }^{5}$. São estas as teorizações:

- As construções hipotéticas introduzidas em Totem e tabu (Freud, 1913/1996f), baseadas na intuição de Darwin segundo a qual a humanidade primitiva se agrupava em pequenas hordas compostas de um macho poderoso e várias mulheres, para

\footnotetext{
${ }^{5}$ Mesmo considerando que a lei bioenergética de Haeckel, o leitimotiv que deu lugar a determinadas especulações, não somente mantém a sua vigência atualmente, mas também influi nos estudos de anatomia comparada (Soriano, 1995).
} 
demonstrar que as instituições humanas, incluindo a religião, derivam de instituições primitivas.

- Os prolongamentos psicolamarckianos inerentes à relação de correspondência entre a neurose de transferência (Übertragunsgsneurose) e a neurose narcísica (nariisstische Neurose) com a filogênese da espécie esboçada por Freud em um trabalho recentemente encontrado na correspondência que o fundador da psicanálise manteve com Ferenczi, intitulado Sinopse das neuroses de transferencia (Freud, 1989/1985).

Estas especulações sobre a origem das instituições humanas e a relação de correspondência entre as neuroses e a filogênese da espécie, não devem ser entendidas como uma adesão cabal às hipóteses de Darwin e de Lamarck ${ }^{6}$. Delouya (1992) adverte que foi na hipótese de Spencer, segundo a qual existe um resumo na mente do indivíduo dos estágios da história da humanidade, que Freud se baseou. Partindo desta hipótese, Freud desenvolveu uma teorização peculiar baseada na transmissão filogenética das lembranças.

A introdução do conceito de fantasias primordiais (Urphantasien) em Um caso de paranóia que contraria a teoria psicanalitica da doensa (Freud, 1915/1996h), reflete este estado de coisas. Definidas como estruturas que modelam e dão historicidade ao complexo de Édipo (Ödipuskomplex), apresentam sua origem numa realidade definida como pré-histórica, que busca enquadrar as singularidades pessoais. São as fantasias de sedução, de castração, de observação da cena primária (coito parental), de retorno à vida intra uterina.A novela familiar pode ser considerada como outra das fantasias promordiais.

Este interesse de Freud pelas origens, presente na relação entre ontogênese e filogênese, reflete, em última instância, sua inquietude naquilo que da ciência se aproxima ao mito. De todo modo, o reconhecimento de Freud sobre a tênue fronteira existente entre mito e ciência o conduz a se distanciar quando havia alguma dívida interna acerca de que estava penetrando demasiado em território alheio, segundo as palavras de Jones (1997, p. 332; tradução dos autores), tomando certa prudência com relação às hipóteses da biologia, não sem reconhecer o caráter de mito científico das suas hipóteses, tal como assinala Grubrich-Simitis (1989). Dentro desta mesma ordem de considerações, na $23^{\mathrm{a}}$ das Conferências introdutórias sobre psicanálise, intitulada Os caminhos da formação dos sintomas (Freud, 1916-1917/1996i), Freud postula $\mathrm{o}$ recurso às fantasias primordiais, quando o vivenciar aparece como rudimentar.

Pois bem, se o evolucionismo de Freud esboçado na variante evolucionista-filogenética-instintual trata, em última instância, sobre as relações entre o homem e a cultura com todas as matizações com

\footnotetext{
${ }^{6}$ Tanto Darwin como Lamarck postulavam que o ambiente produz mudanças hereditárias no organismo (herança dos caracteres adquiridos). Foi Weissman, um dos discípulos de Darwin, que recusou veementemente o mecanismo da herança dos caracteres adquiridos. Entretanto, à diferença de Lamarck que sustentava uma tendência progressiva que obrigaria aos organismos a elevar-se paulatinamente na escala vital, o que revelaria uma teoria da evolução transformacional, Darwin desenvolvia uma teoria variacional da evolução. Ou seja, introduz o princípio da seleção natural na luta pela existência. De todo modo, tal como assinala Soriano (1995), foi o darwinismo que atualizou e colocou em posição de destaque a teoria de Lamarck.
}

que se supõe pensar sobre a passagem do natural ao humano, dado que, neste caso, Freud não se atém a uma idéia positivista de progresso, mas à noção de uma seleção das teorias do mundo testadas pela seleção natural, em Formulacões sobre os dois princípios do funcionamento mental (Freud, 1911/1996e) a adesão às hipóteses evolucionistas efetuase a partir de outra perspectiva.

O estabelecimento de uma psicologia genética (Freud, 1911/ 1996e) demonstra o reflexo da influência que a Escola de Zurich exerceu sobre o pensamento freudiano, em particular Jung. Trata da origem da sexualidade humana e dos seus avatares na adaptação do indivíduo à realidade, a partir da paulatina diferenciação das duas classes de pulsões que compõem o primeiro dualismo pulsional, as pulsões sexuais e as pulsões do ego, incorporadas às pulsões de autconservação, dualismo exposto inicialmente em $A$ concepsão psicanalítica da perturbação psicogênica da visão (Freud, 1910/1996d).

Neste esquema, as pulsões do ego se desenvolvem a partir das pulsões sexuais, estas últimas reguladas pelo princípio de prazer (Lustprinzip). Este processo é correlato ao estabelecimento do princípio de realidade (Realitätprinzip) como princípio regulador do aparelho psíquico. O que desvela a correlação entre o primeiro dualismo pulsional e os dois princípios do funcionamento psíquico. Pois bem, desta singular teorização no seio propriamente dito da psicanálise, depreende-se uma terceira linha de força vinculada com a teoria da evolução, as variantes evolucionistas-ontogenéticas-constitutivas do conceito de pulsão.

As variantes evolucionistas-ontogenéticas-constitutivas referem-se ao modo de pensar a origem e a evolução do aparelho psíquico nos termos de adaptação do organismo-sujeito à realidade e em relação de conflito com a sexualidade. A gênese e a evolução das pulsões sexuais e das pulsões do ego estão inseridas numa concepção de progresso constitutiva e situada dentro de um esquema único em que a adaptação aparece como finalidade. Apresentam uma concepção de realidade endógena e de temporalidade linear e cronológica.

Caberia interrogar neste ponto sobre uma possível equivalência entre as variantes evolucionistas-derivativas e as variantes evolucionistas-constitutivas. Por certo, ambas variantes estão incluídas numa concepção de realidade endógena e biológica, assim como de temporalidade linear e cronológica. Por um lado, a ênfase dada à noção de progresso no sentido de aperfeiçoamento de unidades mais simples (as pulsões sexuais) em direção às as unidades mais complexas (as pulsões do ego), apresenta similitude com a concepção sobre a gênese e a evolução da sexualidade humana esboçada na primeira edição dos Três ensaios... (Freud, 1905/1996b), de 1905. Por outro lado, a equivalência entre as duas variantes se mantém ao cotejarmos as modificações efetuadas por Freud na versão de 1915 dos Três ensaios... (1905/1996b). Nesta versão, Freud atribui um estatuto de organização à sexualidade infantil (do mesmo modo que, antes, havia outorgado à sexualidade adulta), em lugar de um conjunto relativamente caótico e disperso de pulsões, o que se aproximaria do fundamental que se deduz de Formulacões sobre os dois princípios do funcionamento mental (Freud, 1911/1996e), a saber, 
que tanto o modo de funcionamento das pulsões sexuais como o da pulsão do ego são considerados organizações com leis de funcionamento distintas entre si. Nesse sentido, ambas as variantes apontam para uma concepção globalista.

Contudo, a introdução de outro termo na equação não somente no mesmo nível hierárquico que ocupa a sexualidade dentro de uma reflexão propriamente psicanalítica, mas também em oposição a ela, a saber, a adaptação, desemboca em um ofuscamento da noção de sexualidade, ou seja, a adaptação viria a substituir a sexualidade, quando a sexualidade na psicanálise é insubstituível.

Isso se perfila mais nitidamente na ênfase dada ao caráter desadaptado da pulsão sexual na psicopatologia e no desenvolvimento psicossexual normal: o sujeito-organismo, nas palavras de Bercherie (1996), deverá realizar uma "dura aprendizagem de adaptação ao real, conservando a nostalgia da auto-suficiência ilusória da sua vida pré-histórica (p. 372; tradução dos autores).

Por certo, a tela de fundo da teorização presente nestes anos é a concepção profana da sexualidade que viria contaminar os interesses do ego. Auge do primeiro dualismo pulsional, mas também seu ocaso; porque cada descobrimento da teoria da libido, que deveria validálo heuristicamente, colocava-o em questão. A introdução do conceito de narcisismo revelará que o ego está impregnado de sexualidade em todos os momentos de sua constituição e desenvolvimento, o que levaria a questionar o valor heurístico de uma pulsão do ego e de uma pulsão de autoconservação.

Se a variante evolucionista-ontogenética-derivativa aborda a gênese e a evolução da sexualidade humana, na variante evolucionistaontogenética-constitutiva, para além da sexualidade introduz-se outro termo, a adaptação, que mantém com a primeira um conflito, como dois termos antagônicos. A adaptação do sujeito à realidade não necessariamente se opõe aos desígnios da sexualidade.

Assim, a psicologia genética esboçada por Freud em Formulações... (Freud, 1911/1996e) é concebida a partir da perspectiva da adaptação progressiva do organismo à realidade. Um ponto de vista reconhecido pelos desenvolvimentos da biologia, mas que, desde o ponto de vista psicanalítico, equivale a desmentir o suposto sobre a sexualidade inconsciente.

A ênfase na noção de progressão no sentido de aperfeiçoamento de unidades mais simples a unidades mais complexas, do anárquico ao organizado, do pulsional às relações objetais, sem considerar a dinâmica pulsional nas vivências subjetivas do complexo de Édipo e do complexo de castração (Kastrationskomplex), destaca, em última instância, mais um conflito de adaptação do que um conflito pulsional, na medida em que subsume a categoria de sexualidade à de autoconservação, comprometendo, portanto, o estatuto propriamente dito do conceito de fantasia, lembrando que, para Freud, a atividade fantasmática, na sua relação com a sexualidade humana, é inerente ao psiquismo humano e condição necessária do exame de realidade (Realitätsprïfung) e da manutenção da dimensão subjetiva que constitui o sujeito como tal.

Em Além do princípio... (Freud, 1920/1996j), o discurso biológico adquire uma singular especificidade em relação às teorizações anteriores nas quais Freud recorria à biologia. Caracterizado pela especulação sobre a gênese da vida, sobre a relação de oposição entre soma e germe, e sobre a evolução dos seres vivos, este discurso biológico apresenta como pano de fundo a reformulação da teoria das pulsões. Primeiramente concebida como fator que se esforça no sentido da mudança e do desenvolvimento, a pulsão passa a ser entendida como expressão da natureza conservadora da substância viva (Freud, 1920/1996j, p. 47).

É a partir destas especulações que se depreende uma linha de força que, mesmo esboçada na primeira edição dos Três ensaios... (Freud, 1905/1996b), iria revelar-se em Além do princípio... (Freud, 1920/1996j) com toda a sua amplitude e complexidade, a saber, as variantes evolucionistas-filogenéticas-instintuais.

No caso de Além do princípio... (Freud, 1920/1996j), mais do que delinear o vínculo entre pulsão e filogênese, é possível vislumbrar nas variantes evolucionistas-filogenéticas-instintuais toda uma tentativa por parte de Freud de fundamentar uma teorização psicanalítica, especialmente na introdução do dualismo entre pulsões de vida e pulsão de morte, com hipóteses tomadas da biologia, de modo a oferecer uma certa relação de equivalência entre as leis que regulam a matéria orgânica e as leis que regulam o aparelho psíquico.

Referindo-se à falta da proteção anti-estímulo das excitações que provêm do interior do corpo e que podem chegar a perturbações similares às das neuroses traumáticas, Freud introduz o conceito de pulsão como as fontes mais eficazes que emanam do interior do corpo e se transferem ao aparato psíquico, desde logo o elemento mais importante e obscuro da pesquisa psicológica (Freud, 1920/1996j, p. 45). Obscuridade que, além de ser motivo de um singular e complexo desenvolvimento, é incrementada pela definição de pulsão propriamente dita que Freud oferece neste tão emblemático texto. Indagando-se sobre a relação entre o pulsional (não ligado) e a compulsão à repetição (Wiederholungszwang), Freud define a pulsão como um impulso (Drang) inerente ao organismo, que tende a restaurar um estado de coisas precedente (Freud, 1920/1996j, p. 47).

Para postular este condicionamento histórico das pulsões, Freud recorre a determinados fenômenos da vida animal, tais como a migração dos peixes e das aves ao seu ambiente de origem. Segundo Jones (1997), este é o único caso em que Freud recorre às formas de conduta instintiva no campo das ciências naturais. Outro recurso utilizado por Freud para justificar o condicionamento histórico das pulsões são os fenômenos da hereditariedade delineados no lamarckismo de Darwin e a lei bioenergética de Haeckel, segundo a qual a filogênese determina a ontogênese. Freud assinala que o germe de um animal vivo, em lugar de lograr pelo caminho mais curto a sua forma final, está obrigado a repetir (recapitular filogeneticamente) as estruturas de todas as formas das quais se originou e se desenvolveu. Nesse sentido, as características originárias do passado, incluindo-se as modificações posteriores produzidas pelo encontro do organismo com o ambiente, são transmitidas hereditariamente (Freud, 1920/ 1996j). 
O biológico atravessa, assim, a essência propriamente dita da pulsão não como metáfora ou analogia, mas como seu suposto fundamento. $O$ poder conservador da vida se revelaria na repetição filogenética do adquirido e do constitutivo; recapitulação na qual está implícito o movimento mediante o qual se logra alcançar a finalidade da evolução dos organismos. Freud assinala que, desde o princípio da evolução dos organismos, as pulsões orgânicas conservadoras aceitam e preservam para ulterior repetição as modificações impostas aos mesmos, armazenando-as como marcas que cada vez mais se distanciam da finalidade última da evolução dos organismos. Daí a aparente impressão de que as pulsões trabalham no sentido da mudança e do progresso. Mediante vias longas ou curtas, a regressão, forma exterior de repetição, terminará por conduzir o organismo a um fim inscrito em um tempo anterior a sua constituição, a saber, ao estado inorgânico. É assim que se esboça o conceito de pulsão de morte. Freud assinala que, se todo o vivo morre por razões internas, o objetivo de toda vida é a morte, as coisas inamimadas existiram antes das vivas (Freud, 1996j/1920, p. 49).

É dentro desta ordem de considerações, nas quais a reflexão freudiana aparece totalmente do lado de uma especulação biológica, que Freud postula a origem da primeira pulsão, a de regressar ao inanimado. Como primeiro estado de tensão proveniente da passagem do estado inanimado ao animado, esta primeira pulsão surgiria como tentativa de nivelar o excesso de energia. Contudo, não explicita se a pulsão aparece como resultado do processo ou se é equivalente ao estado de tensão (Spilka, 1997).

Pois bem, o que se depreende do assinalado anteriormente não é somente a ausência de qualquer referência ao objeto da pulsão - objeto que, desde os Três ensaios... (Freud, 1996b/1905), aparece como contingente - mas a ausência de bases metapsicológicas, já que não é possível classificar este conceito segundo os seus termos, a saber: fonte, objeto, meta e pressão. Esboça-se também uma reflexão sobre a origem da pulsão que não encontra referência nem no processo repressivo, nem na dimensão fantasmática como fonte da pulsão, tal como adverte Spilka (1997). Cabe assinalar também a advertência de Jones (1997) de que o objetivo da pulsão de regressar ao estado anterior tampouco encontra apoio na biologia. O resultado é a transformação da pulsão em um conceito abstrato.

Para especular sobre a natureza das pulsões, Freud recorre à teoria morfológica de Weismann sobre a duração da vida e da morte dos organismos, segundo a qual a substância viva se constitui de uma parte imortal, o plasma germinal, e uma parte mortal, que é o corpo ou o soma. O plasma germinal favoreceria a copulação entre as células germinativas, dando origem a um novo soma, a um novo indivíduo. Weismann também sustentava a hipótese sobre a imortalidade dos organismos unicelulares, tema muito polêmico na passagem do século XIX ao século XX (Soriano, 1995). Por sua vez, os organismos multicelulares, que produzem a diferenciação entre soma e germe, determinariam a duração limitada da vida. O experimento de Woodruff, um biológo americano, viria a confirmar esta hipótese de Weismann, com a condição de colocar, em cada geração de animáculos, um fluido nutriente novo. Maupas e Calkins, ao contrário, demonstraram a nível experimental a mortalidade dos protozoários. Contudo, a diferença de Woodruff, estes pesquisadores não colocavam fluido novo no animáculo e nos seus descendentes. O que levou Woodruff a concluir que é o próprio produto do metabolismo dos protozoários que os conduzia à morte (Freud, 1996j/1920).

Pois bem, estas especulações revelam um certo paradoxo, visto que a psicanálise não se edifica como teoria sobre a origem da vida, mas como teoria sobre o inconsciente psíquico. Dentro desta mesma ordem de considerações, situando em um mesmo nível a origem da vida e a origem das pulsões, Freud redescreve suas hipóteses referentes às características da pulsão e altera as categorias fundamentais que sustentam a hipótese sobre a sexualidade inconsciente, em detrimento de categorias que pertencem ao campo da biologia. Se todos os organismos buscam assegurar o caminho até a morte, Freud estabelece uma relação de equivalência entre pulsões sexuais e células germinais que, ao se fundirem entre si, trabalham contra a morte da substancia viva (Freud, 1996j/1920:51). Como adverte Spilka (1997), a união das células germinativas supõe uma fixação de objeto que parece adequar-se mais ao campo da necessidade do que da pulsão. Nesse sentido, a dimensão pulsional ficaria subsumida no campo da necessidade, quando é a partir da psicanálise que se tem entendido que a sexualidade não se reduz à função sexual. Tendo, então, se convencido de que todas as pulsões buscam, mediante a compulsão à repetição, restabelecer o estado anterior, entendendo que, no caso da pulsão de morte, este estado anterior corresponde ao retorno à matéria inanimada, Freud interroga qual é a natureza deste retorno ao estado originário no que se refere às pulsões de vida. Recorre, então, ao mito do andrógino, de Platão, para postular como característica da pulsão a necessidade de restabelecer um estado anterior ou seu caráter regressivo, mesmo reconhecendo sua natureza fantástica. Tal como adverte Laplanche (1993), a idéia que se depreende é a de uma sexualidade pré-formada, e de uma busca, da parte do sujeito, por alcançar o que desde o princípio já estava presente; concepção muito diferente da natureza transformadora das pulsões assinalada antes desta mudança radical de perspectiva, ocorrida a partir de 1920.

Uma reflexão mais detida sobre o estatuto do conceito de sexualidade nestes anos remete, pelo menos, a dois aspectos. Por um lado, com as mudanças ocorridas a partir da introdução propriamente psicanalítica do conceito de narcisismo, a sexualidade não será mais concebida como alheia aos desígnios do ego, mas como um princípio necessário para a sua constituição e desenvolvimento. Dito com outros termos, com a concepção de um ego investido de libido, a sexualidade não será mais assimilada ao corpo estranho que atenta contra o bemestar do ego. Por outro lado, a introdução do conceito de pulsões de vida (ou Eros), totalizante, universal, que busca restaurar a unidade perdida, modifica substancialmente a natureza da sexualidade no pensamento de Freud: a noção de sexualidade é ampliada ao ultrapassar o amor sexual, o que conduz a uma concepção humanizada de sexualidade. Essa nova concepção revela um deslizamento semântico entre pulsões sexuais e pulsões de vida ou Eros, tal como assinala Green (1990). Deslizamento que levará Freud a nomear como função sexual as pulsões sexuais, que por sua vez, não devem ser confundidas com Eros, dado que se trata do meio no qual é possível 
aceder a ele. Diz Green (1997), em outro trabalho: Taherzesta denominação [de Eros] não seja tanto mítica, conquanto que busca um modo de expressão apto para reunir os diversos registros de uma vida erótica ampliada numa dimensão a que ninguém, antes de Freud, tinha estendido (Green, 1997, p. 43; tradução e colchete dos autores).

No que se refere à categoria de temporalidade, Além do princípio... (Freud, 1920/1996j) revela os meandros de uma reflexão baseada na crítica que Freud tece a respeito da tese de Kant, segundo a qual tempo e espaço são formas necessárias de pensamento (Kant, citado em Freud, 1920/1996j, p. 39). O que se deduz destas considerações não é uma recusa da temporalidade linear e cronológica, mas a ênfase na intemporalidade dos processos psíquicos inconscientes, que não se ordenam cronologicamente, são inalteráveis com o passar do tempo e dotados de uma temporalidade própria que se expressa na repetição.

Entretanto, muito embora Freud, em Além do princípio... (Freud, 1920/1996j), destaque a intemporalidade dos processos inconscientes, é possível detectar inúmeras contradições e um modo de abordar determinados enunciados que vão alterando sucessivamente as teorizações anteriores. Como assinala Bercheret (1994), cada proposição considerada isoladamente pode parecer em si justificável, mas quando estas proposições se encontram juntas, não somente se excluem entre si, como chegam inclusive a excluir a representação do objeto de partida. O recurso a teorias biológicas, que pareciam a Freud de caráter científico, tais como as de Weismann, Woodruff e Hering, com a finalidade de dar fundamento orgânico à sua teoria das pulsões, não sem deparar-se com a filosofia de Schopenhauer e importar modelos míticos (mito do andrógino, de Platão) para especular sobre a origem das pulsões de vida, inserem-se nesta ordem de considerações.

Assim, Freud recorre a determinadas teorias da ciência natural a fim de dar fundamento orgânico às pulsões de vida e à pulsão de morte. Ocorre entretanto que, como a concepção mecanicista, em particular, a físico-fisiologista da pulsão, explica apenas parcialmente este desenvolvimento teórico, Freud introduz a dimensão da história (Freud, 1920/1996j). Segundo Bercherie (1996), o registro biológico se converte, em Além do princípio... (Freud, 1920/1996j), em um registro único para Freud, irredutível ao campo físico-químico e caracterizado pela dimensão da história. Tentativa que se justifica em Totem e Tabu (Freud, 1913/1996f), em Sinopsis dos neurosis de transferência (Freud, 1989), assim como construção da fantasia primordial. E nada mais útil do que recorrer ao darwinismo, pois nele se conjugam história e biologia. Bercherie assinala que, ao utilizar a fundo um lamarckismo darwinista, Freud termina por criar uma dimensão teórica própria, uma verdadeira teleologia pulsional. De modo que a teoria das pulsões, integrando uma especificidade subjetiva, converte o conflito psíquico em um jogo de forças abismais que se entregam a um combate mítico, eterno e encarniçado (Bercherie, 1996, p. 411).

\section{Considerações Finais}

A partir do exposto nas páginas anteriores, é possível vislumbrar a amplitude e a complexidade que apresenta o recurso de Freud às hipóteses da biologia. Recurso que termina por desembocar numa segunda modalidade discursiva, que mantém com os desenvolvimentos teóricos e clínicos da hipótese estrutural sobre a sexualidade inconsciente uma tensão que, às vezes, parece irresolúvel. Sobretudo quando se confirma que o recurso à biologia na pena de Freud está relacionado com o enigmático da gênese e do desenvolvimento do aparelho psíquico em que a pulsão circula.

No que se refere à dimensão biológica do conceito de pulsão no pensamento freudiano, revelou-se a possibilidade de ordená-la de acordo com determinadas linhas de força, a que se designou de variantes evolucionistas-ontogenéticas-derivativas, evolucionistasfilogenéticas-instintuais e evolucionistas-ontogenéticas-constitutivas. Ordenação que possibilita focalizar o biológico da pulsão em Freud com um olhar mais preciso e menos ofuscado de pré-concepções que, ao conceber o biológico no sentido genérico do termo, terminam por obscurecer questões que ainda merecem esclarecimento e elaboração teórica.

Anteriormente, conjecturamos que o recurso de Freud às hipóteses da biologia ocorreu em um momento inicial de desenvolvimento da sua disciplina, que requereu não somente a importação de seus termos e de modelos, mas também a fundamentação das hipóteses propriamente psicanalíticas. $\mathrm{O}$ que revela que a hipótese que fundamenta a psicanálise como disciplina não é uma operação acabada, mas o início de um processo de reconhecimento de uma outra cena que, para estruturar-se, requer a transmutação de determinadas teorizações numa linguagem metapsicológica. Desvela-se, também, a importância da reflexão sobre a pulsão no rastreamento e no desenvolvimento das categorias psicanalíticas de realidade e de temporalidade, além das demarcadas pela biologia e pelo campo da consciência.

Neste sentido, o desenvolvimento da disciplina inaugurada por Freud permite trilhar outros caminhos que dariam continuidade à tarefa de reformulação conceitual iniciada por ele não no sentido de justificar suas hipóteses, mas de reconhecê-las para, seguindo a gênese de seus movimentos, vislumbrar as suas características, estabelecer uma ponte com os postulados pós-freudianos e, conseqüentemente, buscar uma espécie de ressignificação dos seus enunciados. Mesmo reconhecendo que, nas perspectivas que se apresentam como limítrofes, a psicanálise continua recorrendo aos pontos de vista naturalistas e sociais (Caparrós, 1996). Sinal de que o biológico continua aparecendo como recurso para dar conta de processos que não se decompõem desde o ponto de vista psíquico.

Contudo, o enigmático não deve ser entendido como algo indecifrável, mas como aquilo que estimula nossa curiosidade, instiga uma questão e exige uma resposta. $\mathrm{O}$ que pretendemos sublinhar neste estudo é que, com a expansão propriamente dita da psicanálise, talvez seja possível traduzir numa linguagem metapsicológica os aspectos fronteiriços da reflexão psicanalítica, o que significaria encontrar um princípio explicativo acerca do enigmático da gênese e dos movimentos do aparelho psíquico.

\section{Referências}

Anzieu, D. (1989). A auto-análise de Freud (F. F. Settineri, Trad.). Porto Alegre: Artes Médicas. (Original publicado em 1959) 
Barbosa, M. N. P. (2001). El concepto de pulsión en la obra de Frend. Tese de Doutorado não-publicada, Programa em "Fundamentos y Desarrollos Psicoanalíticos", Universidad Complutense de Madrid. Madrid, Espanha.

Bercheret, J. (1994). Une 'pulsion' qui n'en finit pas de mourir. Revrue Française de Psychanalyse, 58, 361-376.

Bercherie, P. (1996). Génesis de los conceptos freudianos (J. Piatigorsky, Trad.). Buenos Aires: Paidós. (Original publicado em 1983)

Caparrós, N. (1996). Lo esencial en psicoanálisis. Em I. Sanfeliu (Org.), Nuevos paradigmas psicoanalíticos (pp. 13-33). Madrid: Quipú.

Delouya, D. (1992). O biológico em Freud: 'Corpo estranho' ou heresia? Percurso: Revista de Psicanálise, 4, 39-45.

Freud, S. (1989). Sinopsis de las neurosis de transferencia (A. Vincens, Trad.). Barcelona: Ariel. (Original publicado em 1985)

Freud, S. (1996a). A interpretação dos sonhos (W. I. de Oliveira, Trad.). Em J. Salomão (Org.), Edição standard brasileira de obras completas de Sigmund Freud (Vol. 4 e 5). Rio de Janeiro: Imago. (Original publicado em 1900)

Freud, S. (1996b). Três ensaios sobre a teoria da sexualidade (V. Ribeiro, Trad.). Em J. Salomão (Org.), Edição standard brasileira de obras completas de Sigmund Frend (Vol. 7, pp. 117-232). Rio de Janeiro: Imago. (Original publicado em 1905)

Freud, S. (1996c). Caráter e erotismo anal (M. A. M. Rego, Trad.). Em J. Salomão (Org.), Edição standard brasileira de obras completas de Sigmund Freud (Vol. 9, pp. 159-168). Rio de Janeiro: Imago. (Original publicado em 1908)

Freud, S. (1996d). A concepção psicanalítica da perturbação psicogênica da visão (D. Marcondes, J. B. Corrêa, W. I. Oliveira, D. Mussa, C. S. Costa, J. Salomão \& P. D. Corrêa, Trad.). Em J. Salomão (Org.), Edição standard brasileira de obras completas de Sigmund Freud (Vol.11, 217-228). Rio de Janeiro: Imago. (Original publicado em 1910)

Freud, S. (1996e). Formulações sobre os dois princípios do funcionamento mental J. O. A. Abreu, Trad.). Em J. Salomão (Org.), Edição standard brasileira de obras completas de Sigmund Freud (Vol. 12, pp. 221-230). Rio de Janeiro: Imago. (Original publicado em 1911)

Freud, S. (1996f). Totem e tabu (O. C. Muniz, Trad.). Em J. Salomão (Org.), Edicão standard brasileira de obras completas de Sigmund Freud (Vol. 13, pp. 11-164). Rio de Janeiro: Imago. (Original publicado em 1913)

Freud, S. (1996g). A disposição à neurose obsessiva. Uma contribuição ao problema da escolha da neurose (J. O. A. Abreu, Trad.). Em J. Salomão (Org.), Edição standard brasileira de obras completas de Sigmund Frend (Vol. 12, pp. 335-350). Rio de Janeiro: Imago. (Original publicado em 1913)

Freud, S. (1996h). Um caso de paranóia que contraria a teoria psicanalítica da doença (T. O. Brito, P. H. Brito \& C. M. Oiticica, Trad.). Em J. Salomão (Org.), Edição standard brasileira de obras completas de Sigmund Freud (Vol. 14, pp. 267-284). Rio de Janeiro: Imago. (Original publicado em 1915)

Freud, S. (1996i). Conferências introdutórias sobre psicanálise (J. L. Meuer, Trad.). Em J. Salomão (Org.), Edicão standard brasileira de obras completas de Sigmund Frend (vol. 15 e 16). Rio de Janeiro: Imago. (Original publicado em 1916-1917)

Freud, S. (1996j). Além do princípio de prazer (E. A. M. Souza, Trad.). Em J. Salomão (Org.), Edição standard brasileira de obras completas de Sigmund Freud (Vol. 18, pp. 11-76). Rio de Janeiro: Imago. (Original publicado em 1920)
Freud, S. (1996k). A organização genital infantil: Uma interpolação na teoria da sexualidade (J. O. A. Abreu, Trad.). Em J. Salomão (Org.), Edição standard brasileira de obras completas de Sigmund Freud (Vol. 19, pp. 153-162). Rio de Janeiro: Imago. (Original publicado em 1923)

Freud, S. (19961). Um estudo autobiográfico (C. M. Oiticica,Trad.). Em J. Salomão (Org.), Edicão standard brasileira de obras completas de Sigmund Freud (Vol. 20, pp. 10-78). Rio de Janeiro: Imago. (Original publicado em 1925)

Freud, S. (1996m). Projeto para uma psicologia científica (J. L. Meurer, Trad.). Em J. Salomão (Org.), Edição standard brasileira de obras completas de Sigmund Frend (Vol. 1, pp. 333-450). Rio de Janeiro: Imago. (Original publicado em 1950)

Gay, P. (1989). Freud. Una vida de nuestro tiempo (J. Piatigorsky, Trad.). Barcelona: Paidós. (Original publicado em 1988)

Green, A. (1990). De locuras privadas (J. L. Etcheverry, Trad.). Buenos Aires: Amorrortu. (Original publicado em 1986)

Green, A. (1997). Las cadenas de Eros. Actualidad de lo sexual (I. Argoff, Trad.). Buenos Aires: Amorrortu.

Grubrich-Simitis, I. (1989). Metapsicología y metabiología. Em S. Freud, Sinopsis de las neurosis de transferencia (A. Vicens, Trad.). Barcelona: Ariel. (Original publicado em 1985)

Jones, E. (1997). Vida y obra de Sigmund Frend, Tomo III (M. Carlisky, Trad.). Buenos Aires: Lumen-Hormé. (Original publicado em 1960)

Kristeva, J. (1998). El escándalo fuera del tiempo. Em Libro anual del psicoanálisis (Vol. I, pp. 109-127). Madrid: Biblioteca Nueva.

Laplanche, J. (1973). Vida y muerte en psicoanálisis (M. Horne, Trad.). Buenos Aires: Amorrortu. (Original publicado em 1970)

Laplanche, J. (1993). El extravio biologizante de la sexualidad en Freud (S. Bleichmar, Trad.). Buenos Aires: Amorrortu.

Laplanche, J. \& Pontalis, J. B. (1983). Vocabulário da Psicanálise (P. Tamen, Trad.). São Paulo: Martins Fontes. (Original publicado em 1967)

Laplanche, J. \& Pontalis, J. B.(1988). Fantasia originaria, fantasias das origens, origens da fantasia (A. Cabral, Trad.). Rio de Janeiro: Jorge Zahar. (Original publicado em 1985)

Perron, R. (1991). Des diverses sens du terme 'modèle' et de leurs usages possibles en psychanalyse. Revue Française de Psychanalyse, 55, 222-231.

Ricoeur, P. (1970). Freud: Una interpretación de la cultura (A. Suárez, Trad.). México: Siglo XXI. (Original publicado em 1965)

Sandler, J. (1982). Reflexiones sobre algunas relaciones entre los conceptos psicoanalíticos y la prática psicoanalítica. Revista de Psicoanálisis, 39, 579-596.

Soriano, J. F. (1995). Psicoanálisis y biologia. Aspectos convergentes. Valencia: Promolibro. Spilka, J. (1997). Reflexiones en torno a "Más allá del principio de placer". Revista de Psicoanálisis, 26, 83-106.

Sulloway, F. J. (1981). Freud, biologiste de l'espirit (J. Lelaidier, Trad.). Paris: Librairie Arthème Fayard. (Original publicado em 1979)

Recebido: 21/03/2004 Aceite Final: 06/04/2004

Sobre os autores

Maria Nadeje Pereira Barbosa é Master em Teoria Psicanalítica e Doutora em Psicologia pela Universidad Complutense de Madrid. É bolsista recémdoutora na Universidade de São Paulo, Ribeirão Preto.

Manoel Antonio dos Santos é Mestre e Doutor em Psicologia Clínica pela Universidade de São Paulo. É bolsista produtividade do CNPq e Professor na Universidade de São Paulo, Ribeirão Preto. 